\title{
SENTIDOS SUBJETIVOS RELACIONADOS COM A MOTIVACְÃO DOS ESTUDANTES DO CLUBE DE CIÊNCIAS DA ILHA DE COTIJUBA
}

\author{
José Moysés Alves* \\ Wilton Rabelo Pessoa** \\ Ana Sgrott $* * *$ \\ Janes Kened Rodrigues dos Santos**** \\ Patrícia Feitosa Santos***** \\ Luiz Carlos Silva Conceição*****
}

RESUMO: Objetivamos, no presente estudo, conhecer os sentidos subjetivos que afetam a motivação dos estudantes do Clube de Ciências da Ilha de Cotijuba. Entrevistamos 6 estudantes sobre suas atividades, o projeto que estavam realizando, suas relações com os professores, colegas, familiares, e sobre suas aulas de Ciências na escola. Os estudantes mencionaram qualidades de suas relações interpessoais e características das atividades que os motivavam a participar do Clube e das aulas de Ciências na escola. Também apontaram problemas infraestruturais e circunstanciais que desencorajavam tal participação. Os aspectos destacados, alguns específicos desse contexto histórico-cultural, aparecem em configurações subjetivas ligeiramente diferentes para cada estudante. O enfoque adotado nos pareceu adequado para compreender a motivação dos estudantes de uma forma sistêmica.

Palavras-chave: Subjetividade; Motivação; Clube de Ciências.

\section{SUBJECTIVE SENSES RELATED TO THE MOTIVATION OF STUDENTS FROM THE SCIENCE CLUB OF COTIJUBA ISLAND}

ABSTRACT: We aim in this study to know the subjective senses that affect students' motivation to participate in the Science Club from Cotijuba Island. We interviewed six students on their activities, the project they were doing, their relationships with teachers, colleagues, family and their Science classes at school. Students mentioned qualities of interpersonal relationships and characteristics of activities, which motivated them to join the club and Science classes in school. They also pointed out infrastructural problems and circumstances that discouraged such participation. These aspects, some specific of the historical and cultural context, appear in slightly different subjective configurations for each student. The approach taken seemed appropriate to understand the motivation of students in a systemic way.

Keywords: subjectivity; motivation; science club.
*Bacharel em Psicologia pela Universidade Federal do Pará (UFPA). Mestre em Educação Especial pela Universidade Federal de São Carlos (USFCAR). Doutor em Psicologia pela Universidade de São Paulo (USP).

E-mail: jmalves@amazonet.com.br

* * Licenciado em Química pel Universidade Federal do Pará (UFPA). Mestre em Educação em Ciências e Matemática pela Universidade Federal do Pará (UFPA). E-mail: wiltonrabelo@yahoo.com.br

** * Licenciada em Matemática pela Universidade Federal de Santa Catarina (UFSC).

Mestre em Ensino de Ciências e Matemática pela Universidade Federal do Pará (UFPA). E-mail: anasgrott@ig.com.br

*** * Licenciada em Ciências Naturais com Habilitação em Química pela Universidade Federal do Pará(UFPA). Mestre em Educação em Ciências e Matemática pela Universidade Federal do Pará(UFPA). E-mail: janeskened@yahoo.com.br

***** Licenciada em

Matemática pela Universidade da Amazônia (UNAMA). Mestre em Educação Matemática pela Universidade Federal do Pará (UFPA). E-mail: pat.feitosa@yahoo.com.br

****** Licenciado em Ciências Biológicas pela Universidade Federal do Pará (UFPA). Mestre em Educação em Ciências e Matemáticas pela Universidade Federal do Pará (UFPA). E-mail: luizcsconceicao@gmail.com 


\section{INTRODUÇÃO}

Inerente a toda atividade humana, a afetividade está, inevitavelmente, presente na produção do conhecimento científico. Tal compreensão nos leva a contestar aqueles que concebem a ciência e a educação científica como atividades neutras, isentas de valores e produtoras de conhecimentos objetivos. Concordamos com Reiss (2005, p.17), para quem "a objetividade da ciência de certa forma exige que a ciência e as emoções operem em mundos separados".

Pesquisar a dimensão afetiva em aulas de Ciências implica enfatizar a intersubjetividade constitutiva do processo de ensino e aprendizagem. Isso requer conceber professor e estudantes como pessoas dotadas de afetos, e não apenas de intelectos (REY, 2006).

Ensina-se aos estudantes, predominantemente, os resultados do conhecimento científico, que são apresentados como verdades descobertas. Os processos de sua produção permanecem ocultos para a maioria deles. Tal ensino tem sido criticado por transmitir visões distorcidas da ciência e também por contribuir para a desmotivação dos estudantes relacionada à aprendizagem de Ciências (CACHAPUZ, 2005). Pesquisas mostram que atitudes favoráveis em relação à ciência diminuem à medida que se avança nas séries escolares (REISS, 2005).

Diferentemente desse contexto, parece haver um aumento do interesse na ciência fora da escola. Segundo Reiss (2005), isso pode ser notado pela frequência de programas de ciências na televisão e no rádio; pelo crescimento dos museus de ciência; e por haver uma tendência em se revelar como locais de educação científica espaços tais como zoológicos e jardins botânicos. O sucesso da educação científica fora da escola deve-se, provavelmente, ao fato de trazer ao público em geral temas atuais e relevantes e apresentá-los de forma interessante.

Conhecemos poucos estudos sobre a dimensão afetiva em aulas regulares de Ciências e, menos ainda, em contextos de educação que não ocorrem no âmbito da escola. Pesquisar a motivação para aprender Ciências, a nosso ver, requer conhecer os sentidos subjetivos que os estudantes atribuem à sua participação nas atividades destinadas a ensiná-los. Segundo Rey (2006, p. 34/35):

\footnotetext{
Os sentidos subjetivos... são expressões de uma teia simbólico-emocional na qual as emoções, sentidos e processos simbólicos de procedência muito diferentes integram-se na definição das diversas configurações subjetivas que acompanham os diferentes tipos de atividades humanas.
}

Segundo o mesmo autor, o sentido subjetivo integra aspectos da história individual com momentos atuais da vida, permitindo representar o envolvimento afetivo do sujeito na atividade. Desta forma, "os sentidos subjetivos constituem verdadeiros sistemas motivacionais" (REY, 2006, p. 33).

As emoções que os estudantes experimentam no processo de aprendizagem não estão relacionadas, exclusivamente, com as atividades destinadas a 
ensiná-los, mas com sentidos subjetivos que se originam em diferentes momentos de suas vidas.

Daí a importância de considerar o sujeito que aprende na complexidade de sua organização subjetiva, pois os sentidos subjetivos que vão se desenvolvendo na aprendizagem são inseparáveis da complexidade da subjetividade do sujeito (REY, 2006, p. 34).

A constituição da subjetividade acontece na relação dialética entre sua dimensão constitutiva e sua dimensão construída; isto é, entre a dinâmica dos processos de construção e reconstrução permanente do sujeito no aqui e agora e a história do sujeito, resultante das interações entre fatores biológicos, culturais e ontogenéticos. A subjetividade é um macroconceito que possibilita abordar ambas as dimensões de forma integrada (BRANCO E MADUREIRA, 2005).

Os Clubes de Ciências foram pensados para oportunizar uma aprendizagem de ciências diferenciada da aprendizagem escolar. Nesse contexto, é esperado que os estudantes, ao se envolverem em atividades de produção de conhecimento, além de construirem uma nova concepção sobre a natureza da ciência, se motivem para estudá-la.

Entretanto, como Rey (2005, p. 36), entendemos que "pensar em tipos de motivação padronizada para atividades específicas é uma reminiscência de uma psicologia sem sujeito". Encontramos apoio a esta ideia em Nieswandt (2005, p. 48), que ao revisar estudos sobre atitudes em relação à ciência, afirma ser necessário ver as salas de aula como espaços complexos e dinâmicos, que “...são preenchidos com indivíduos (alunos e professores) que têm uma variedade de razões e motivos para estar naquela sala em particular e se comprometer com a aprendizagem".

Neste sentido, consideramos que apesar de ser pensado como um espaço de troca de ideias e de pesquisas que motiva os alunos a aprenderem Ciências (MANCUSO et al, 1996), o Clube de Ciências e o ensino com pesquisa, por si mesmos, não garantem que tal motivação seja alcançada.

Casanova e Alves (2011) realizaram uma pesquisa com estudantes da $8^{\mathrm{a}}$ série do Ensino Fundamental que participaram de um projeto sobre plantas medicinais. Verificaram que a participação no projeto não mudou, de forma marcante, as metas de realização e autoconceitos dos estudantes. Ainda assim, estudantes que apresentaram metas de aprendizagem e autoconceito positivo, ou que mudaram o autoconceito negativo inicial, alcançaram melhores níveis de participação e aprendizagem durante o projeto. Entretanto, os autores encontraram resultados de sujeitos individuais que contrariavam as tendências grupais, como por exemplo sujeitos que apresentaram autoconceito positivo, mas que alcançaram níveis de participação e aprendizagem regular ou insuficiente. Tais resultados carecem de explicação em uma abordagem da motivação que a concebe como um conjunto de variáveis separadas e as relaciona com características das tarefas, verificando correlações entre variáveis. Além disso, demandam uma abordagem qualitativa, que compreenda como tais características se relacionam da perspectiva de um sujeito particular. 
A teoria da subjetividade de Rey, a nosso ver, responde a essa demanda. Segundo Rey (2005, p. 36), “a motivação será o tipo de configuração subjetiva que está na base da produção de sentidos subjetivos. Portanto, a motivação define-se no sujeito e pelo sujeito, e não pelo tipo de atividade".

Considerando a importância e, apesar disso, a escassez de estudos sobre a motivação para aprender Ciências, especialmente em contextos de educação extraescolares, e considerando a relevância de realizar tal pesquisa na perspectiva da epistemologia qualitativa, objetivamos, no presente estudo, conhecer os sentidos subjetivos relacionados com a motivação de estudantes do Ensino Fundamental e Médio para participarem do Clube de Ciências da ilha de Cotijuba. Especificamente, buscamos compreender as configurações de sentidos subjetivos dos estudantes sobre suas atividades no clube, suas relações com professores, colegas e familiares, e sobre suas aulas de Ciências na escola.

\section{MÉTODO}

\section{Situação e sujeitos da pesquisa}

Realizamos a pesquisa com estudantes da Ilha de Cotijuba, que se localiza em frente à Icoaraci, a cerca de $20 \mathrm{~km}$ do centro de Belém. O acesso à Ilha é feito através de barco. A travessia, a partir de Icoaraci, dura aproximadamente 40 minutos.

A ideia de formar uma turma de extensão do Clube de Ciências da UFPA em Cotijuba partiu de um professor da disciplina Física que atuava na única escola da ilha e que havia sido professor-estagiário, durante sua graduação, no Clube de Ciências da UFPA, em Belém. Ele tinha interesse em desenvolver um trabalho de ensino com pesquisa, respeitando as particularidades do contexto no qual estava inserido.

O Clube de Ciências de Cotijuba funciona desde 2009 e tem cinco professores-estagiários, das áreas de Pedagogia, Química, Física, Biologia e Matemática. Eles são os responsáveis por elaborar e desenvolver atividades para os alunos da educação básica da Ilha, sob a orientação de um professor da coordenação do Clube de Ciências de Belém.

Participaram como sujeitos da presente pesquisa seis estudantes do Clube de Ciências de Cotijuba, sendo três rapazes e três moças, com idades variando de 15 a 19 anos. Todos estudavam na Escola Estadual de Ensino Fundamental e Médio "Marta da Conceição", a única sob a responsabilidade do Estado, na Ilha. Atribuímos nomes fictícios aos sujeitos: Ana (19 anos) e Caio (19 anos), do $2^{\circ}$ ano do Ensino Médio; Susi (15 anos) e Lia (16 anos), do $1^{\circ}$ ano do Ensino Médio; Marco (15 anos) e Fábio (15 anos), da 8 a série do Ensino Fundamental.

\section{Procedimento de coleta das informações}

Coletamos as informações para o presente estudo entrevistando, separadamente, cada um dos seis estudantes. As entrevistas duraram em média 40 
minutos e foram registradas em gravadores de voz digitais. Elas tiveram por base o seguinte roteiro, que elaboramos previamente: 1. Tua família é daqui mesmo? Há quanto tempo moras aqui? 2. O que tu fazes além de estudar? 3. Como tu conheceste o Clube de Ciências? 4. Por que tu quiseste participar do Clube? 5. $\mathrm{O}$ que tu gostas de fazer no Clube? 6. Tem alguma coisa que tu gostarias que fosse diferente? 7. O que tu achas dos teus professores? O que tu já aprendeste com eles? 8. O que tu achas dos teus colegas? O que tu já aprendeste com eles? 9. Fora os professores e colegas, tu já aprendeste com outras pessoas alguma coisa que serviu para a atividade do Clube? Com quem? Como foi? 10. O que tu ainda não sabias e aprendeste aqui? E o teu projeto? De onde surgiu a ideia? A que resultados tu pretendes chegar? 11. O que tu achas das tuas aulas de ciências na escola? Como são as aulas? O que tu aprendes nelas? Costumas ter aulas práticas? Tu gostas? O que tu aprendes nelas?

\section{Procedimento de análise}

Cada entrevista foi integralmente transcrita e analisada, focalizando os aspectos que consideramos pertinentes ao nosso estudo. Depois de lermos e relermos as entrevistas transcritas, notamos que apesar das diferenças, os sentidos subjetivos produzidos pelos estudantes tinham muito em comum. Resolvemos organizar os resultados em seis categorias, incluindo as características gerais das atividades do Clube, que da perspectiva dos estudantes motivavam sua participação, a relevância que atribuíam ao projeto de pesquisa que estavam realizando, a avaliação que faziam das suas relações com os professores, com os colegas e com os familiares, bem como o sentido subjetivo que tinha para eles suas atividades escolares. Ilustramos, com trechos dos relatos dos participantes, semelhanças e diferenças apontadas por eles em relação a cada um desses tópicos. Em seguida, com apoio na literatura, comentamos as perspectivas apresentadas, buscando compreender como se configurava subjetivamente para os estudantes a motivação para participar das atividades do Clube de Ciências.

\section{RESULTADOS E DISCUSSÃO}

Em termos de semelhanças na configuração subjetiva de todos os estudantes, verificamos que eles pretendem estudar para melhorar de vida, mas enfrentam o problema de falta de professores na escola. Gostam das aulas de Ciências e das atividades do Clube. Estão entusiasmados com seus projetos de pesquisa, que focalizam questões relevantes para a Ilha. Admiram seus professores de Ciências, apesar de alguns destacarem a inexperiência dos estagiários. Aprendem com os colegas, mas algumas vezes divergem deles. Também aprendem lições de vida com os familiares e trocam experiências com eles. 


\section{MOTIVOS PARA PARTICIPAR DO CLUBE DE CIÊNCIAS}

Os alunos gostam das atividades realizadas no Clube de Ciências porque nelas podem participar ativamente, como destaca Lia: Acho legal o modo como eles ensinam, porque eles não são como antes que só jogavam o trabalho lá, só explicavam, e aí os alunos não perguntam quase nada. Aqui a gente tem oportunidade de participar.

As atividades favorecem a reflexão, a investigação e a alegria de descobrir, como aponta Fábio: Eu gosto do clube... eles fazem a gente pensar, raciocinar, porque muitas vezes na escola jogam o conteúdo em cima da gente, a gente só faz. ler aquilo, praticamente gravar, nem estuda, só faz gravar aquilo. Aqui eles fazem a gente pensar, iniciar uma pesquisa. Cada descoberta é uma alegria.

Participar, refletir, pesquisar, descobrir coisas novas, são condições bem conhecidas na literatura como favorecedoras do desenvolvimento do senso crítico, da autonomia e da motivação dos estudantes. Segundo Nieswandt (2005), vem se intensificando a crença de que o melhor tipo de educação inclui o desenvolvimento do raciocínio autônomo e a autodeterminação dos estudantes.

Os estudantes não deixam de apontar algumas limitações do Clube no que se refere à organização e infraestrutura, como reclama Susi: Acho que lá é muito desorganizado, às vezes as coisas ficam sujas... Acho que precisa de uma melhor estrutura, pra ficar uma coisa mais bonita.

Chegam a apontar divergências entre a teoria ensinada no Clube e a prática dos familiares, reivindicando um diálogo com os saberes da comunidade, como fez Ana, que desenvolveu uma pesquisa sobre o uso de adubos orgânicos no cultivo de hortaliças: Eu aprendi com a minha familia que é "desse modo", ai quando eu fui plantar semente de alface pra apresentar na feira de Ciências do jeito que eles (Clube) ensinaram, não deu certo. Mas quando eu fui plantar do jeito que a minha família me ensinou, deu certo. Aí, pôxa, como é que isso aconteceu? A gente deveria não só ficar na parte teórica, mas fazer mais a prática, conversar com as pessoas, tipo um diálogo, uma troca de conhecimentos do pessoal do Clube com o daqui (ilha).

$\mathrm{O}$ incentivo para não serem indiferentes e nem se inibirem de fazer críticas construtivas, propondo melhoramentos para o Clube, deriva, provavelmente, da prática do diálogo, que implica em respeitar e valorizar a opinião dos estudantes, considerando-os, de fato, como sócios-mirins. O trabalho em equipe é uma característica importante do ensino pela pesquisa e, segundo Lima (2004, p.285):

... pressupõe vivências capazes de tornar os sujeitos socialmente competentes. Cooperação, solidariedade, exercício de direitos e deveres são algumas atitudes que aperfeiçoam o senso de cidadania e são largamente experienciadas quando a proposta é constituição de grupos de pesquisa. 


\section{RELEVÂNCIA SOCIAL E MOTIVAC̣ÃO PARA PESQUISAR}

Os estudantes demonstram estar motivados e pessoalmente envolvidos na elaboração e execução de suas pesquisas. Tal envolvimento é expresso nos sentidos subjetivos que assumem para eles sua participação na elaboração de ideias, no convívio e estudo com professores e colegas, na possibilidade de reelaboração de estratégias metodológicas das pesquisas e, principalmente, na relevância social das pesquisas, que prometem retorno de conhecimentos e benefícios para a comunidade local.

Os estudantes estão envolvidos na elaboração de ideias para a escolha da temática das pesquisas, como aponta Marco, que teve muitas ideias no decorrer (da pesquisa)... Porque en sempre queria fazer o melhor de mim. Eu queria ter várias ideias, en tive sobre urbanização, sobre saneamento, sobre fossas, eu pensei até em pulga de cachorros.

Tal processo de levantamento de ideias e definição da temática envolve o estudo e a convivência em grupo, como relata Fábio: [...] a gente foi convivendo com os professores, fomos estudando sobre solo, sobre alimentos, a ideia (do projeto) foi surgindo ao longo do tempo, ai fomos achando (o trabalho) bom, uma boa pesquisa.

É interessante perceber, nas falas de Marco e Fábio, o envolvimento intelectual e afetivo que eles manifestam ao falar sobre seus projetos. O levantamento de muitas ideias no decorrer do projeto está relacionado, nas falas de Marco, ao anseio de fazer o melhor de si. Do mesmo modo, a convivência e o estudo com professores e colegas possibilitou, segundo Fábio, a escolha da temática e, ao mesmo tempo, um sentimento de satisfação em relação ao trabalho, considerado pelo grupo uma boa pesquisa.

Estes resultados apoiam os que defendem o ensino com pesquisa na escola, ressaltando a importância de cada estudante comprometer-se com a própria aprendizagem. Segundo Nieswandt (2005, p. 23), "a educação científica escolar só é susceptível de ser bem sucedida quando os alunos acreditarem que a ciência que está sendo ensinada tem valor pessoal para eles próprios".

Ao se envolverem intelectual e afetivamente na elaboração e desenvolvimento de suas pesquisas, os estudantes atribuem sentidos diversos e singulares em relação às temáticas em investigação. Ao falar de sua pesquisa sobre alimentos orgânicos, Caio destaca que é um assunto um pouco polêmico porque o produto tradicional fica bom para o consumo muito mais rápido, o capital vem bem mais rápido também, enquanto que o orgânico precisa de mais mão de obra, mais dinheiro, é mais caro, não fica bom para o consumo tão rápido quanto o inorgânico.

Em sua fala, Caio estabelece relações de custo e benefício entre o produto tradicional e o orgânico. Isso, a nosso ver, constitui um exemplo de reflexão que contribui para um processo de tomada de decisão na perspectiva do exercício da cidadania (SANTOS E SCHNETZLER, 2000).

O principal aspecto considerado pelos estudantes na escolha das temáticas é a relevância social da investigação para a comunidade local, como nos diz Marco, que decidiu estudar sobre arraias porque as pessoas por ai são ferradas [...] e não tem uma proteção [...], não sabem quais áreas tem mais arraias. 
Além do retorno para a comunidade, a participação dos estudantes em atividades no sentido da "identificação, diagnóstico e solução de problemas" pode trazer respostas atuais a importantes problemas de pesquisa da área de ensino de Ciências e Matemática (MORTIMER, 2002).

\section{A EXPERIÊNCIA E O INCENTIVO DOS PROFESSORES}

Os estudantes gostam muito de seus professores, acreditam que foram auxiliados por eles, como relata Ana: Ah, eles são muito bacanas. Eles nos ajudaram bastante... E o fato de eles serem professores ajuda, porque eles passam a experiência deles pra gente (...), principalmente quando fazem correlações dos conteúdos com o cotidiano da ilha.

Porém, fazem clara distinção entre professores experientes e professores-estagiários: mas tem muitos alunos universitários que não sabem explicar pra gente o que eles estão aprendendo na universidade; na hora de passar as coisas pra gente eles se atrapalham muito, eles não sabem passar o que eles acham, o que eles aprenderam (Ana). A opinião de Caio é semelhante: às vezes eles não preparam uma aula, uma aula adequada. Às vezes ele trazem uma aula, um tipo de aula, só que às vezes não dá certo e eles não têm uma outra coisa pra ensinar entendeu? Eles ficam meio perdidos.

Mesmo assim, acreditam que aprendem com eles e, ao mesmo tempo, os ensinam: Mas também com eles eu aprendi a me expressar melhor com as pessoas, mesmo porque eu sempre gostei de trabalhar sozinha, mas com eles não, aprendi a fazer trabalho em grupo, a ouvir a opinião das pessoas, a me expressar melhor... Ao mesmo tempo em que eu aprendo, eles também tão aprendendo comigo (Ana).

Os alunos selecionam, categorizam e interpretam as informações relativas aos seus professores de maneiras diferentes, a partir de critérios distintos. $\mathrm{O}$ aluno tem uma imagem do "professor ideal" e essa imagem é idiossincrática a cada aluno. Coll et al (2000) destacam como fatores afetivos importantes na construção da imagem do professor pelos alunos a disponibilidade do professor, o respeito, o afeto que transmite ao aluno e a capacidade de mostrar-se acolhedor e positivo. Os autores afirmam que o peso de tais fatores é maior no início da escolaridade.

No caso de nossos sujeitos, que estavam na $8^{a}$ série, ou no Ensino Médio, constatamos que além dos recursos que o professor tem para motivar e envolver os alunos, eles valorizam o conhecimento que o professor tem da matéria ministrada, como relata Fábio: no curso prático do Fortalecer ${ }^{1}$ eles perguntavam coisas pra gente que a gente não sabia, sobre experiências... Que todo ácido reage com uma base, a gente não sabia disso. De acordo com as experiências que o professor Carlos fez, a gente foi aprendendo. Também Marco destacou a importância da interação com o professor para sua motivação: O que me motivou primeiro, sinceramente, foi o professor Carlos. Ele que veio me motivar a ter o gosto pela ciência. Antes eu nem sabia o que era (...) ele faz de um jeito que a aula dele fica interessante.

Esses resultados vão ao encontro da afirmação de Rey (1997, p. 104), que considera o professor como "parte essencial do sentido subjetivo da disciplina 
que ministra, portanto, o desenvolvimento de suas relações representa uma fonte importante no desenvolvimento da motivação relacionada com tal disciplina”.

\section{A CONVIVÊNCIA E A APRENDIZAGEM PARTILHADA COM OS COLEGAS}

Os estudantes têm boa relação com os colegas, mas diferenciam os que ajudam e os que atrapalham, destes se afastando. São solidários, mas se aborrecem com os que zombam de seus esforços, como comenta Ana: a maioria sabe, coloca a alma mesmo naquele objetivo principal, que é passar de ano, mostrar o que aprendeu, mostrar que o projeto é bom, que podem ganhar bolsa... Mas tem alguns que não estão nem aí pra essas coisas... Mas a maioria se esforça muito...

Os estudantes relatam sobre o que aprenderam com os colegas. Lia destaca o aprendizado de conteúdos acadêmicos... aprendi o modo como eles trabalham; por exemplo, eles estão me ensinando como fazer o relatório, porque ano que vem, assim quando eu começar a pesquisa, eu já tenho que ter mais ou menos uma base. Fábio conta que os colegas lhe ensinam conteúdos extraescolares: A gente aprende a fazer coisas de improviso. Fora de casa a gente quer fazer alguma coisa, uma brincadeira assim, quer fazer uma jangada... a gente faz de garrafa. Susi focaliza aprendizados relacionados ao crescimento pessoal: Aprendi a ter paciência com as outras pessoas, a ouvir a opinião dos outros alunos. Mas tem muitos que não dão a devida importância pra o que aprendem no clube. A galera precisa muito de alguém que "puxe", senão eles acabam não fazendo nada.

Além de aprenderem com os colegas sobre conteúdos acadêmicos e extraescolares, o trabalho em grupo propicia aprendizagens sobre o mundo social, contribuindo para a alfabetização emocional. Segundo Alsop (2005), a alfabetização emocional inclui, entre outras, as capacidades de entender nossas emoções, de escutar os outros e ter empatia pelas suas emoções, de melhorar relacionamentos, possibilitar o trabalho cooperativo e facilitar o sentimento de comunidade. $\mathrm{O}$ autor comenta resultados de pesquisa, afirmando que no trabalho em grupo os estudantes aprendem sobre cada colega e começam a ficar mais relaxados com as diferenças que percebem. Os estudantes constroem uma melhor compreensão de si e dos outros e ganham confiança, o que contribui para a aprendizagem.

\section{AS LIC̣ÕES DOS FAMILIARES COMO CONSTITUTIVAS DA MOTIVAC̣ÃO}

O exemplo de persistência dos pais, suas histórias de luta para educá-los, também motiva os alunos para continuarem estudando, como aponta Sara: Sabe, na minha família ninguém é formado. Todos tiveram que largar os estudos e trabalhar cedo. Mas o que eu aprendi é que apesar deles terem passado por todas as dificuldades, eles nunca desistiram dos filhos, e lutaram pra que eles tivessem uma vida melhor.

Outro aspecto importante da relação dos estudantes com os seus familiares é a troca de aprendizagens e conhecimentos entre eles, como destaca Marco: Ele 
[pai] gosta de plantar, mas ele não sabia diferenciar alimentos orgânicos de inorgânicos. Tem muitos pais que não gostam que os alunos, os filhos, expliquem nada. Meu pai deixa [...] é uma troca de conhecimentos

Existe também o auxílio por parte de familiares mais relacionados com a formação acadêmica e que também trazem contribuições significativas ao aprendizado dos alunos, como afirma Caio: O meu irmão, ele é universitário, ele sempre vem aqui, ele sempre me dá dica de como se apresentar (trabalho) aqui na frente... ele me ajudou também a fazer esse trabalho, essa pesquisa que eu vou fazer sobre o camarão.

Apesar de estar passando por transformações que a diferenciam do que era há algumas décadas, a família continua sendo um dos alicerces principais para a formação das gerações posteriores. Isso não acontece apenas em relação ao mundo acadêmico e profissional, mas também em relação à formação de indivíduos como cidadãos (Carvalho, 2004).

\section{EXPECTATIVAS E FRUSTRAC̣̃̃ES RELACIONADAS COM A ESCOLA}

Os alunos estão muito descontentes com a escola, principalmente por causa da carência de professores: Aqui na escola a gente tem muita carência de professores. Às vezes a gente fica com menos da metade dos professores (Susi). A gente só tem professor de Geografia desde o comeco do ano. Só teve acho que a primeira avaliação de Geografia, só. Esse ano mesmo tá ruim (Fábio). Aqui na escola tá em falta alguns professores, a gente só tem quatro professores: Biologia, Física, Português e Matemática, o resto ou tá doente ou não tem mesmo (Ana).

A dificuldade de acesso à Ilha de Cotijuba explica, pelo menos em parte, a carência de professores na escola. A carência de professores, por sua vez, contribui para a desmotivação dos alunos, como justifica Lia: Nem todo mundo sabe se vai passar ou não, porque tá com duas matérias e quase ninguém tá se esforçando, porque pra passar só em duas matérias, e as outras, como a gente vai ficar?

Os estudantes também reclamam de outras condições da escola: Tá faltando muita coisa. Tá faltando biblioteca, sala de informática também tá em falta. Assim quando a gente quer pesquisar tem que ir lá no cyber, assim fica mais difícil, mas no geral eu gosto muito de estudar (Ana).

Apesar das carências, os estudantes relatam gostar das aulas de Ciências. Os conteúdos às vezes interessam por serem contextualizados, como destaca Susi: Eu aprendo a explicar melhor alguns fenômenos que a gente percebe, tá vendo no dia a dia, mas não sabia explicar... principalmente em Biologia, que a professora Rosa fala muito sobre o corpo bumano, o que é melhor, sobre o tipo de relacionamento com as pessoas.

Outras vezes, os conteúdos interessam por fazerem parte do projeto de futuro do estudante, como indica Marco: As vezes tem muita coisa complicada de Química, tem cálculo, mas isso que me interessa porque eu tenho que lutar por aquilo que eu quero.

Uma das características avaliadas positivamente nas aulas de Ciências é o trabalho em grupo, como relata Lia: Nas aulas de Física eu aprendo... Porque antes o professor Cézar passava mais trabalho, assim para gente fazer em grupo, a gente não explicava o 
trabalho, só escrevia, às vezes fazia alguns testes individuais. Agora a gente tá fazendo trabalho em grupo, a gente vai pra frente mesmo e explica o trabalho para os outros colegas e tenta responder às perguntas. Também é uma característica destacada por Susi: Gosto muito de Biologia... eu sempre tomo a iniciativa nos trabalhos em grupo, eu sempre me interesso muito... E o trabalho em grupo ajuda a gente até a se expressar melhor lá na frente da turma.

Outra característica das aulas de Ciências, vista como positiva, são as aulas práticas, como relata Ana: Ah, eu gosto mais das aulas de Ciências porque a gente tem mais aula prática... Em Biologia, por exemplo, a gente faz muita excursão pela ilha, pra identificar algumas espécies. Isso não acontece na turma de Susi, que reclama, justamente, da falta desse tipo de atividade: Eu acho também que a gente devia ter mais aula prática, sair um pouco mais da sala de aula. A gente mora numa ilha, e, por exemplo, na aula de Biologia e Física, a gente deveria explorar mais as coisas da ilha, pra aprender mais com a natureza mesmo, e não só em sala de aula.

Segundo Wellington (2005), os professores geralmente afirmam que o trabalho prático motiva os estudantes, mas poucas pesquisas investigaram a opinião dos estudantes a esse respeito. $\mathrm{O}$ autor relata que os estudantes valorizam o trabalho em grupo, mas apresentam algumas reservas. Os resultados que obtivemos, tanto os relacionados às experiências no Clube de Ciências, quanto os relacionados à escola, confirmam os resultados de Wellington (2005) e apontam a necessidade de outras pesquisas para maior aprofundamento sobre a motivação dos estudantes nas aulas práticas.

\section{CONSIDERAC̣̃̃ES FINAIS}

Inspirados na epistemologia qualitativa de Rey (2006), lançamos a hipótese de que aquilo que motiva os estudantes a participarem do Clube de Ciências da Ilha de Cotijuba se expressa nos sentidos subjetivos que eles atribuem às atividades que realizam e a suas relações com professores e colegas. Também entendemos que a motivação se constitui em sentidos subjetivos que se originam em outros contextos que não o Clube de Ciências, especificamente, a família e a escola.

Os resultados que obtivemos confirmam nossas hipóteses e mostram que os estudantes valorizam uma série de aspectos que também têm sido apontados na literatura da área como motivadores do processo de ensino/aprendizagem. Resumidamente, podemos mencionar como aspectos que afetam positivamente a motivação, entre outros identificados pelos adolescentes, as oportunidades de participarem, de forma ativa, reflexiva, crítica, investigativa, autônoma e alegre, das atividades do Clube; o trabalho em grupo; a contextualização de seus projetos em problemas locais, socialmente relevantes; a ajuda que eles recebem de seus professores, que detêm conhecimentos e estratégias para envolvê-los nas atividades; a solidariedade dos colegas e o exemplo de persistência dos pais. Entre os aspectos que afetam negativamente a motivação para aprender Ciências, os estudantes identificaram, entre outros, os problemas de infraestrutura da escola e do Clube de 
Ciências; a falta de diálogo dos professores com a comunidade; a carência de professores na escola e, consequentemente, a ameaça de não concluírem o ano letivo; a inexperiência, insegurança e falta de conhecimento de alguns dos professores estagiários; bem como os colegas que atrapalham e zombam dos seus esforços.

Tais aspectos, que afetam positiva ou negativamente a motivação dos estudantes, se organizam de formas ligeiramente diferentes para cada um deles. Acreditamos que o fato de encontrarmos muitas semelhanças entre eles se dá pelas semelhanças em suas histórias de vida, sua faixa etária e por vivenciarem os mesmos contextos: a ilha, a escola e o Clube de Ciências.

Cabe destacar alguns aspectos que são específicos desse contexto, mesmo que não tenham aparecido na fala de todos os estudantes. Em primeiro lugar, destacamos o exemplo dos pais, que não tiveram oportunidades de escolarização e que lutaram para conseguir educá-los. Isso incentiva os estudantes a estudar e compõe seus projetos de vida para o futuro, tais como cursar faculdade, pós-graduação, ter uma profissão, ajudar a família, etc. Ao comentar suas relações com os colegas, Ana expressou esse sentido subjetivo de forma contundente:

Ás vezes a gente diz assim um pro outro: "olha não desiste, essa é uma oportunidade única, teus pais não tiveram essa oportunidade que tu tá tendo, tem mais é que aproveitar". Porque como aqui é uma ilha, tem pessoas carentes aqui... A maioria ganha, pôxa, um salário, e como a forma de melhorar de vida é estudar, a gente dá força um pro outro.

Entretanto, especialmente pela carência de professores, sentem-se desmotivados a estudar na escola, dada a probabilidade de não concluírem o ano letivo, como explicitou Lia:

Antes eu me interessava mais, agora, tô menos ... antes se o professor marcava um trabalho para entregar, no dia marcado eu entregava, naquele dia; agora a gente tá assim, mais jogado, porque só tem duas matérias. Ai, porque nem todo mundo sabe se vai passar ou não, porque só tem duas matérias, quase ninguém tá se esforçando, porque pra passar só tem duas matérias. E as outras como a gente vai ficar?! Porque se passar nessas duas, a gente não sabe se vai conseguirpassar pro segundo ano só com duas matérias ... ainda falta mais da metade.

Ao mesmo tempo em que os pais lutam por melhores condições de vida e incentivam seus filhos a estudarem e se profissionalizarem, o sistema educacional lhes nega esse direito e os ameaça a desperdiçarem esforços, sem a perspectiva de atingirem suas metas.

Segundo Carvalho (2004), desde a década de 1990 a família tem sido convocada a participar da escola, mas, ao mesmo tempo, está sendo responsabilizada pelo sucesso ou fracasso escolar. Por mais que o incentivo familiar aos estudos seja algo positivo para a educação escolar, a família não deve ser considerada como o único fator responsável pelo sucesso ou fracasso escolar.

Outra especificidade do contexto, bem aproveitada pelos professores do Clube, foi o fato de incentivarem os estudantes a escolherem, para tema de seus 
projetos de pesquisa, problemas locais da Ilha de Cotijuba, socialmente relevantes. Um bom exemplo é o de Susi, que se interessou

\begin{abstract}
pelo desmatamento em Cotijuba, porque eles desmatam muito a terra pra poder vender o terreno... como é que fica a qualidade do solo depois que queimam as árvores e tiram toda a vegetação? A partir dos resultados de sua pesquisa, ela espera mostrar para as pessoas o quanto a ilha está sendo prejudicada com isso, e assim conscientizar essas pessoas de tudo isso que está acontecendo aqui na ilha.
\end{abstract}

De outro modo, talvez por inexperiência, os professores deixaram de considerar os saberes da comunidade e perderam oportunidades de dialogarem com os pais dos alunos sobre assuntos de interesse comum, como a plantação de alface. Os comunitários são bem sucedidos na plantação de alface, enquanto os professores do Clube, embora propondo variação nas condições de plantio, não obtiveram o mesmo sucesso.

O diálogo entre os saberes escolares e comunitários é um aspecto recomendado para o ensino de Ciências, a partir de tendências atuais da área. Para Chassot (2003, p. 195/196), por exemplo,

\footnotetext{
uma possibilidade de se fazer uma pesquisa participante na área da Educação Química pode ser traduzida no resgatar a Química que está inserida na realidade física e social vivenciada pelos estudantes (ou em outras realidades) e analisar com eles, de forma dialógica, os diferentes significados atribuídos ao conhecimento e as diferentes formas de construção deste conhecimento.
}

No presente estudo, obtivemos resultados diferentes daqueles produzidos por pesquisas que separam variáveis motivacionais e as correlacionam através de testes estatísticos. Tais resultados confirmam a ideia de que a motivação não está apenas relacionada com as características das atividades de ensino, mas se origina em outros contextos, inclusive naqueles que fazem parte da história passada do sujeito, de acordo com o sentido subjetivo que tais situações assumem para ele. A abordagem qualitativa que adotamos nos possibilitou explorar de forma sistêmica uma variedade de crenças, que da perspectiva subjetiva dos estudantes os motivam a participar do Clube e a estudar Ciências.

Nossos resultados indicam que os estudantes estão bastante satisfeitos e motivados com suas atividades no Clube de Ciências. Entretanto, construímos tais indicadores a partir dos relatos dos estudantes, sem observar como a participação no Clube acontecia efetivamente e quais aprendizagens de conhecimento científico dela resultavam. Sugerimos que futuras pesquisas investiguem tal processo, levando em conta a dimensão construída da motivação e da aprendizagem, além de sua dimensão constitutiva. 


\section{REFERÊNCIAS}

ALSOP, S. Bridging the Cartesian divide: science education and affect. In: Alsop, S. (Ed). Beyond Cartesian Dualism: Encountering affect in the teaching and learning of science. The Netherlands: Springer, 2005. p. 3-16.

BRANCO, A. U. e MADUREIRA, A. F. A. A noção de sujeito na ciência psicológica: Linguagem e Constituição da subjetividade em discussão. In: Rey, F. G. (Org.) Subjetividade, Complexidade e Pesquisa em Psicologia. São Paulo: Pioneira Thomson Learning, 2005. p. 127-153.

CARVALHO, M. E. P. Modos de educação, gênero e relações escola-família. Cadernos de Pesquisa. v. 34, n. 121, p. 41-58, jan./abr. 2004.

CACHAPUZ, A. et al. A necessária renovação do ensino das ciências. São Paulo: Cortez, 2005. 263 p.

CASANOVA, M. P.; ALVES, J. M. Metas de realização e autoconceito de estudantes de Ciências em contexto de ensino com pesquisa. Submetido à Ciência e Educação, 2011.

CHASSOT, A. Alfabetização científica: questões e desafios para a educação. 3 ed. Editora Unijuí: Ijuí, Rio Grande do Sul, 2003. 438 p.

COLL, C.; MIRAS, M. A representação mútua professor/aluno e suas repercussões sobre o ensino e a aprendizagem. In: COLL, C. et al. Desenvolvimento psicológico e educação. Volume 2: Psicologia Educacional. Porto Alegre: ARTMED, 1996. p 265-280.

COLL, C. et al. Psicologia do Ensino. Porto Alegre: Artmed, 2000. 408 p.

LIMA, V. M. R. Pesquisa em sala de aula:um olhar na direção do desenvolvimento da competência social. In: MORAES, R.; LIMA, V. M. R. (Org.). Pesquisa em sala de aula: tendências para a Educaşão em Novos Tempos. 2 ed. Porto Alegre: EDIPUCRS, 2004. v. 1, p. 275-291.

MANCUSO, R.; LIMA, V. M. R.; BANDEIRA, V. A. Clubes de Ciências: criação, funcionamento, dinamização. Porto Alegre: SE/CECIRS, 1996.

MORTIMER, E. F. Uma agenda para a pesquisa em Educação em Ciências. Revista Brasileira de Pesquisa em Educação em Ciências. Porto Alegre, 2 (1), p. 25-35, 2002.

NIESWANDT, M. Attitudes toward science: a review of the field. In: ALSOP, S. (Ed.) Beyond Cartesian Dualism: Encountering Affect in the Teaching and Learning of Science. The Netherlands: Springer, 2005. p. 41-52.

REISS, M. J. The importance of affect in science education. In: ALSOP, S. (Ed.) Beyond Cartesian Dualism: Encountering Affect in the Teaching and Learning of Science. The Netherlands: Springer, 2005. p. $17-25$.

REY, F. G. A subjetividade social e sua expressão no ensino. Temas em Psicologia, 3, p. 95-107, 1997.

REY, F. G. O sujeito que aprende: desafios do desenvolvimento do tema da aprendizagem na psicologia e na prática pedagógica . In: Tacca. M. C. V. R. (Org.) Aprendizagem e Trabalho Pedagógico. 1 ed. Campinas: Alínea, 2006. p. 29-44.

SANTOS, W. L. P.; SCHNETZLER, R. P. Educasão em Quimica: Compromisso com a cidadania. Ijuí: Ed. UNIJUÍ, 2000.

WELLINGTON, J. Practical work and the affective domain: what do we know, what should we ask, and what is worth exploring further? In: ALSOP, S. (Ed.) Beyond Cartesian Dualism: Encountering Affect in the Teaching and Learning of Science. The Netherlands: Springer, 2005. p. 99-109.

Data do Recebimento: 23/03/2011

Data de Aprovação: 16/10/2011

Data da Versão Final: 20/03/2012 